\title{
A CFD Modeling Study Based on Relative Humidity Effect on PEMFC Performance
}

\author{
Safiye Nur Özdemir ${ }^{1}$ İmdat Taymaz ${ }^{1 *}$ \\ 0000-0003-1337-7299, 0000-0001-5025-5480 \\ ${ }^{1}$ Mechanical Engineering Department, Faculty of Engineering, Sakarya University, Sakarya, 54187, Turkey
}

\begin{abstract}
Water management is a crucial parameter that significantly affects the uniform distributions of current density and cell voltage, durability, and working life of the fuel cell. In this investigation, three dimensional steady model was proposed for Z-type and U-type geometry and numerical simulations were fulfilled using commercial computational fluid dynamics (CFD) ANSYS FLUENT to investigate the impact of reactant humidification on cell performance and water management. CFD results were shown on polarization and power curves to observe the relative humidity $(\mathrm{RH})$ effect on maximum power point tracking. The results demonstrated that cell performance could be improved significantly by decreasing $\mathrm{RH}$ of the cathode inlet gas from 100 to $10 \%$ at high current densities. Increasing $\mathrm{RH}$ of the anode gas inlet from 10 to $100 \%$ at low operating voltages resulted in a superior performance. It was noted that convenient humidification of the reactant was essential.
\end{abstract}

Keywords: CFD model; PEMFC; Relative Humidity; Water Management

\section{Research Article}

https://doi.org/10.30939/ijastech..931807

$\begin{array}{ll}\text { Received } & 03.05 .2021 \\ \text { Revised } & 22.05 .2021 \\ \text { Accepted } & 25.06 .2021\end{array}$

Accepted 25.06.2021

* Corresponding author

İmdat Taymaz

taymaz@sakarya.edu.tr

Address: Mechanical Engineering Department, Faculty of Engineering, Sakarya University, Sakarya, Turkey

Tel:+903122028653

\section{Introduction}

Proton exchange membrane (PEM) fuel cell technology, compared to traditional thermal power systems, is an important power source, especially in automotive applications, for the past decade. Many scientists have focused on designing a far superior system to other energy sources in the market. PEM fuel cells can be considered as high-efficiency power sources, not exceeding the Carnot efficiency. Reactant humidification is mandatory to ensure high ionic conductivity, homogeneous distributions, low ohmic voltage loss, and an increment in PEM-FC performance [1]. Water flooding may occur on the cathode electrode due to its combined effect of the water produced at the end of the electrochemical reaction and the water transferred to the cathode by electro-osmotic drag resulting in a difficult reactant transport [2-3]. Consequently, water management plays an important role in the efficient and stable operation of PEMFC, and a certain level of humidification should be the basis for best performance [4]. Lots of work have been conducted on the effect of reactant humidification on the PEM-FC performance. Ahmed et al. prepared a full 3D single-cell model with phase conversion to observe the effect of reactant humidification on PEM-FC performance. As a result of the combination of high hydrogen and low cathode humidity, it was concluded that the PEM fuel cell had the best performance in terms of heat and water management [5]. Jian et al. proposed a computational fluid dynamics (CFD) model to investigate the effect of the anode and cathode humidification ranging from dry to full humidified on current density and temperature change affecting battery efficiency. When the relative humidity of the hydrogen was kept $0 \%$ or $50 \%$, the higher temperature difference was obtained by increasing the relative humidity of the oxygen. The results showed that increasing hydrogen humidification significantly improved cell performance at low humidification and the same operating conditions [6]. Yuan et al. assessed the impacts of the operating parameters (e.g., relative humidity, stoichiometric ratio, pressure, and temperature) related to thermal and water management on PEM-FC performance by modeling and simulating the 3D, multi-phase CFD model. Better power output was achieved with the increase in temperature and pressure. Oxidant humidification has a less significant effect on performance compared to hydrogen humidification. Oxygen consumption and the removal rate of the water increase as the stoichiometric ratio rises to a certain value without membrane dehydration [7]. Zhang et al. investigated the humidification impact on power density using PEMFC with a $4.4 \mathrm{~cm}^{2}$ active area at high temperatures. Cell performance was significantly adversely affected when the relative humidity gradually decreased from $100 \%$ to $25 \%$. Increasing relative humidity can eventuate faster electrode 
kinetics and higher membrane proton conductivity [8]. Mohammadzadeh et al. studied the impacts of the different working parameters, including anode channel humidification, the stoichiometric ratio of the hydrogen, cell temperature, and current density on water management criteria. Non-isothermal, the 2D model has been performed to simulate the size of the water droplets using a single-region mechanism. A Fortran code was used to solve the governing equations. They found that increasing current density has an insignificant effect on the droplet size [9]. Wang et al. investigated the impacts of RH levels on the cell performance, liquid water saturation distribution, and membrane water content with the multiphase, three-dimensional PEM-FC model for the counterflow and co-flow patterns. They revealed that combinations of fully humidified hydrogen with low moisture oxygen or fully humidified oxygen and low moisture hydrogen had induced an increase in cell performance at the low cell potentials and decreased cell performance at the high cell potentials [10]. Iranzo et al. performed experimental work to observe the varying operating conditions (current density, reactant humidification, and stoichiometry) on liquid water distributions using the neutron radiography approach. It was concluded that cathode humidification strongly influenced cell performance compared to anode humidification [11]. Ozen et al. tested the different operating conditions (temperature and reactant humidity) experimentally to get maximum efficiency using PEM-FC with a $25 \mathrm{~cm}^{2}$ active area. The results illustrate that better cell performance was obtained with oxygen humidification and temperature increase [12]. Jeon et al. generated a 3-D CFD model with serpentine flow field arrangement using the commercial software STAR-CD. They studied the effect of different cathode relative humidity levels on temperature, current density distributions, and water management. They reported that cathode humidification strongly influences the performance based on the current density and temperature distributions [13]. This paper investigates the cell performance specifications of a single PEMFC under various humidification levels of hydrogen and oxidant gases. 3D numerical isothermal and steady model with an active area of 4.41 $\mathrm{cm}^{2}$, including Z-type and U-type arrangements, was developed to investigate the humidification effect on water management and cell performance numerically.

\section{Material and Method}

\subsection{Geometric model}

The three-dimensional isothermal model with two different arrangements, namely, Z-type and U-type, was generated to examine the impacts of the cathode and anode humidification on the performance of a low-temperature PEMFC. The numerical model employed in the present study is depicted schematically in Figure 1. The flow channel depth and width are $1 \mathrm{~mm} .21 \times 21 \mathrm{~mm}^{2}$ active area numerical model with Z-type and U-type flow field configurations were imported as Parasolid file in ANSYS MESHING 2021 R1 tool for meshing goal. The single-cell model was discretized using the finite volume method. The effect of element number on current density should be examined for mesh independence work since the model was generated using the finite element method. A numerical model was solved for 1 million, 6 million, and 10 million elements. The current densities were found as $0.8398,0.84,0.841 \mathrm{~A} / \mathrm{cm}^{2}$ at $0.60 \mathrm{~V}$ when the computational domain consists of 1 million, 6 million, and 10 million elements, respectively, for U-type arrangement. According to the numerical findings, no significant change was detected in the current density, and the number of 6 million elements was sufficient for mesh structure. The above operations were also repeated for the Z-type arrangement. In this study, hydrogen was completely humidified, relative oxygen humidity was defined as $10 \%, 50 \%$, and $100 \%$, respectively, and numerical simulations were performed for three different flow geometries.

Similarly, oxygen was fully humidified, relative hydrogen humidity was determined as $10 \%, 50 \%$, and $100 \%$, respectively; results were compared and discussed on polarization and power curves. Reactant pressure at the cathode and anode was $303975 \mathrm{~Pa}$. The operating temperature was maintained at $343 \mathrm{~K}$. The stoichiometric ratio of the reactants supplied to the flow channels is 2 .

\subsection{Model assumption}

To employ the PEMFC numerically, the model necessitates the following assumptions; PEMFC operates in a steady-state manner. Hydrogen and oxidant gas flow has been considered as singlephase, laminar and incompressible. The electrode and porous layers are taken into account as isotropic permeable zones. Reaction and ohmic heating have been regarded. Electrochemical reactions occur on the catalyst layer.

\subsection{Boundary conditions and solution strategy}

The discretized CFD model export file from ANSYS MESHING 2021 is imported in Fluent 2021 R1 for satisfying the proper boundary conditions. The conservation of mass is linked with the Navier-Stokes equation through a SIMPLE algorithm, and convergence criteria are enabled using a doubleprecision option. Governing equations are solved numerically by ensuring Fuel Cells and Electrolysis module. The open cell potential for the scaled-up models is defined as $1.1 \mathrm{~V}$. The inlet velocities of hydrogen and oxidant are calculated for the numerical study with the following equations.

$$
\begin{aligned}
& u_{a, \text { in }}=\xi_{a} \frac{I}{2 F} A_{M E A} \frac{1}{X_{H_{2}, \text { in }}} \frac{R T_{a, \text { in }}}{P_{a, \text { in }}} \frac{1}{A_{c h}} \\
& u_{c, \text { in }}=\xi_{c} \frac{I}{4 F} A_{M E A} \frac{1}{X_{O_{2}, \text { in }}} \frac{R T_{c, \text { in }}}{P_{c, \text { in }}} \frac{1}{A_{c h}}
\end{aligned}
$$

$\mathrm{X}$ is the oxygen/hydrogen molar fraction, $\mathrm{I}$ is the mean current density, and $\mathrm{A}_{\mathrm{MEA}}$ is the active area. Table 1 illustrates the boundary and electrochemical characteristics of the entire threedimensional PEMFC model. Hydrogen and oxidant are humidified in specific amounts, not ensured directly through the flow field to prevent membrane drying. The wall type was defined on 
the surfaces of the current collector plates. Continuity was applied on the interface surface between the MEA and gas diffusion layer. Model equations were solved using a finite volume method. The numerical solution was obtained based on a SIMPLE algorithm in the ANSYS FLUENT. BCGSTAB (Bi-conjugate gradient stabilized method) and F-cycle as a multigrid approach were changed for all equations. The model was solved with Intel(R) Core(TM) i7-7700HQ CPU $2.80 \mathrm{GHz}$ processor and $16 \mathrm{~GB}$ RAM. Each numerical solution converged at the end of 500 iterations and lasted about $8 \mathrm{~h}$ for each case.
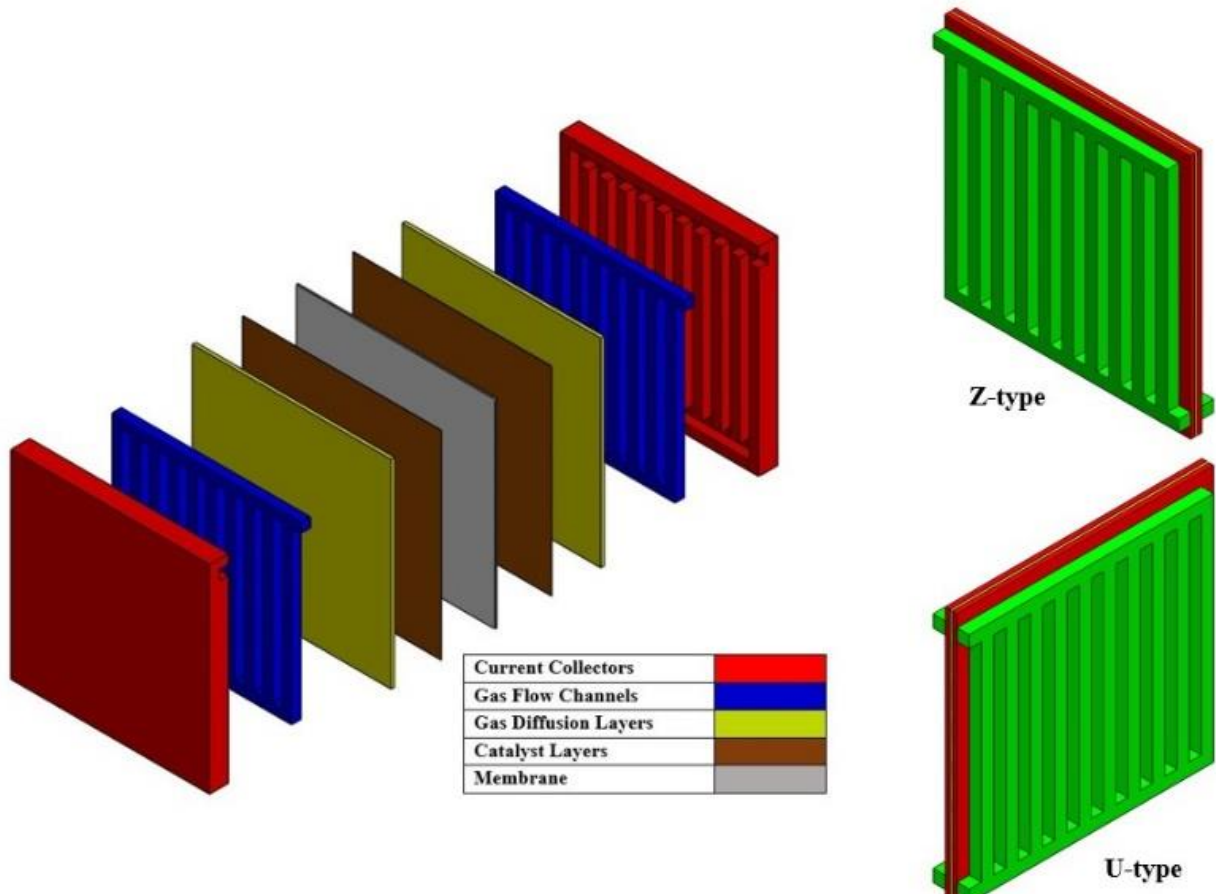

Fig. 1. Schematic pictures of 3D PEMFC with Z-type and U-type arrangements

Table 1. Physical and electrochemical properties in the simulation

\begin{tabular}{c|c}
\hline Input Parameters & Value \\
\hline Open Cell Voltage $(\mathrm{V})$ & 1.1 \\
\hline Electrode Porosity on the Anode & 0.7 \\
\hline Electrode Porosity on the Cathode & 0.7 \\
\hline Hydrogen Stoichiometry & 2 \\
\hline Oxidant Stoichiometry & 2 \\
\hline Electric Potential on the Anode $(\mathrm{V})$ & 0 \\
\hline Electric Potential on the Cathode $(\mathrm{V})$ & 0.25 to 1 \\
\hline RH on the Anode Side & $10 \%, 50 \%, 100 \%$ \\
\hline RH on the Cathode Side & $10 \%, 50 \%, 100 \%$ \\
\hline Operating Pressure $(\mathrm{Pa})$ & 303975 \\
\hline Cell Temperature $\left({ }^{\circ} \mathrm{C}\right)$ & 70 \\
\hline Reference Current Density on the Anode $\left(\mathrm{A} / \mathrm{m}^{2}\right)$ & 10000 \\
\hline Reference Current Density on the Cathode $\left(\mathrm{A} / \mathrm{m}^{2}\right)$ & 20 \\
\hline Reference Concentration $\left(\mathrm{kmol} / \mathrm{m}^{3}\right)$ & 1 \\
\hline Exchange Coefficient & 2 \\
\hline Species Reference Diffusivity $\left(\mathrm{m}^{2} / \mathrm{s}\right)$ & $3 \times 10^{-5}$ \\
\hline Membrane Equivalent Weight $(\mathrm{kg} / \mathrm{kmol})$ & 1100 \\
\hline Viscous Resistance for CL $\left(1 / \mathrm{m}^{2}\right)$ & $1 \times 10^{12}$ \\
\hline Viscous Resistance for GDL $\left(1 / \mathrm{m}^{2}\right)$ & $1 \times 10^{12}$ \\
\hline Concentration Exponent on the Anode & 0.5 \\
\hline Concentration Exponent on the Cathode & 1 \\
\hline
\end{tabular}




\section{Results and Discussions}

PEM fuel cell performance depends on two main operating parameters: temperature and relative humidity related to water management. Water management is an essential criterion for PEM fuel cell or stack operation, durability, and stability. The membrane must be moistened to a certain amount for the transport of hydrogen ions through the membrane. Otherwise, a dry membrane will create resistance to the protons carried from the anode to the cathode. On the other hand, water flooding may occur in the gas flow channel, restricting the mass transfer to the electrode surface. Both conditions result in the degradation of cell performance. Water flooding and membrane drying are directly associated with fuel cell design and operating condition.

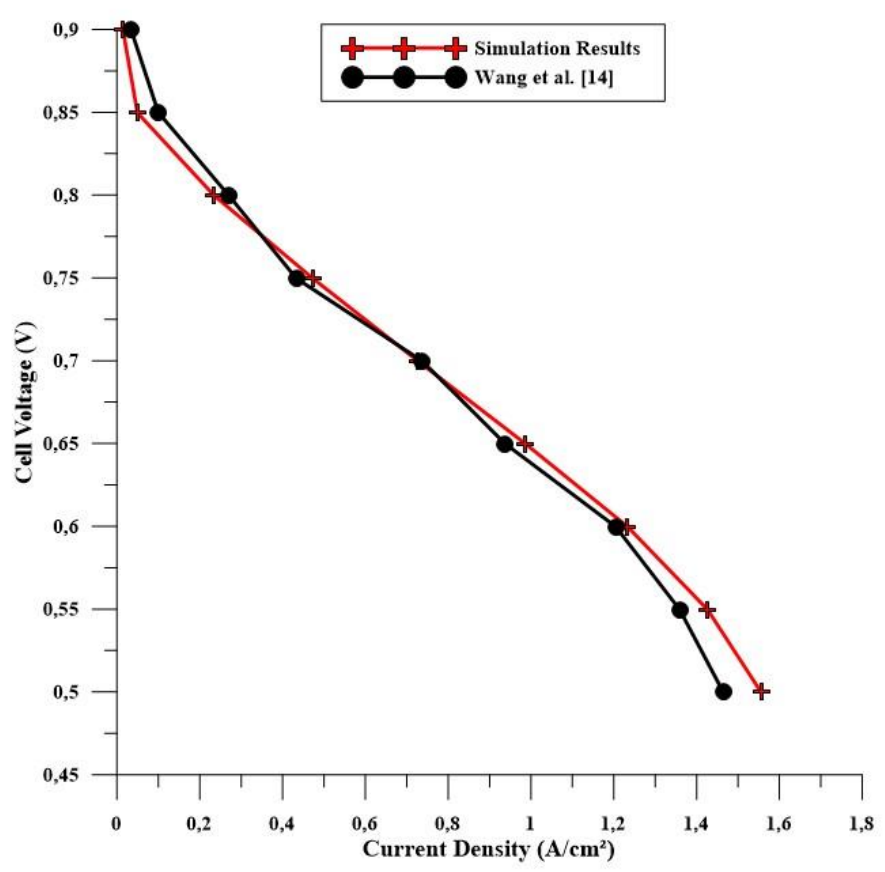

Fig. 2. Numerical validation of the current density of the 3D PEMFC

In this part, CFD results for the Z-type and U-type flow field patterns are discussed. We investigated the effect of the humidification of the reactant gases on cell performance for two different arrangements. To validate the CFD model, the simulation results generated in Ansys Fluent are compared with the experimental results reported by Wang et al. [14]. It is noted that the numerical data are in perfect agreement with experimental data given in Fig. 2 . Since the numerical solution has occurred based on single-phase modeling, the deviation between the experimental and numerical results will emerge due to the phenomenon of water flooding, especially at high current densities.

\subsection{Effect of the anodic humidification}

In this section, the cathode side of the PEMFC is fully humidified. The anodic relative humidities have been varied as $10 \%, 50 \%$, and $100 \%$, respectively, and the impact of the anode humidification on PEM-FC performance has been investigated. Simulation results are shown as polarization (I-V) and power density (I-P) curves in Fig. 3 and Fig. 4. According to the numerical results, higher power densities were obtained with increasing anode humidification, and cell performance improved. The highest power densities were obtained in both $\mathrm{U}$ and $\mathrm{Z}$ type flow field designs at $0.65 \mathrm{~V}$. The power densities are $0.6905,0.7096,0.7169 \mathrm{~W} / \mathrm{cm}^{2}$ when the anode humidification rates are $10 \%, 50 \%$ and $100 \%$, respectively for Z-type arrangement. Protons passing through the membrane carry some water to the cathode side using electro-osmotic drag. When the anode side is sufficiently moistened, the protonic conductivity of the membrane increases, resulting in higher current and power densities. The gas flow on the anode side should be humidified by a certain amount to prevent membrane dehydration. It is concluded that the highest cell performance is achieved when the anode side is fully humidified. Kahveci and Taymaz [15] demonstrated in their investigation that higher current and power densities are obtained by increasing the anode humidification. The highest power density is recorded as $0.5060 \mathrm{~W} / \mathrm{cm}^{2}$ in the fully humidified U-type flow field design condition.

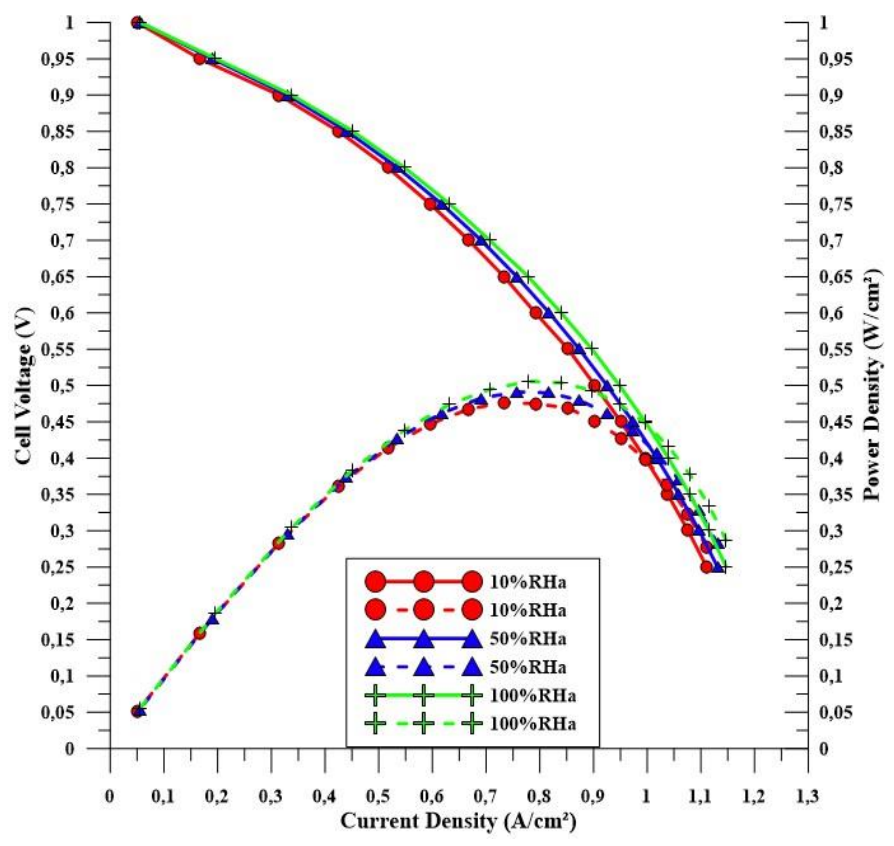

Fig. 3. Effect of RH at the anode on the polarization curve at fully humidified cathode condition for Z-type arrangement 


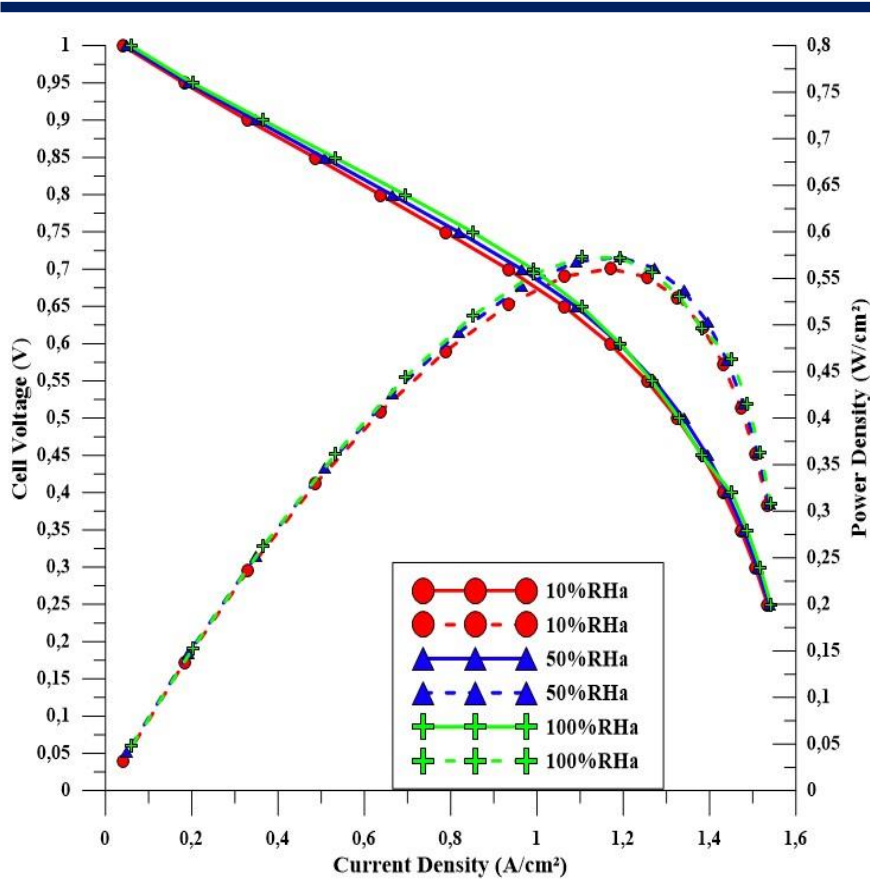

Fig. 4. Effect of RH at the anode on the polarization curve at fully humidified cathode condition for U-type arrangement

\subsection{Effect of the cathodic humidification}

This section outlines the anode side of the PEMFC is fully moistened. The cathode side humidities have been determined as $10 \%$, $50 \%$, and $100 \%$, respectively, and the impact of the air humidification on cell performance has been analyzed. CFD results are expressed as I-V and I-P curves to observe the cathode's RH effect in Fig. 5 and Fig. 6. According to the numerical results, higher power densities were obtained with decreasing cathode humidification at lower operating voltages. The power densities are 0.4086 , $0.3993,0.3855 \mathrm{~W} / \mathrm{cm}^{2}$ when the cathode humidification rates are $10 \%, 50 \%$ and $100 \%$, respectively for Z-type arrangement. Excessive moisture on the cathode side causes an increase in water production in the cathode catalyst layer. Excessive water accumulation on the cathode side disrupts the water balance between the cathode and anode, which causes the water to diffuse in the opposite direction, known as back diffusion. As a result, the membrane's pores begin to clog, and the transport of the species becomes difficult. The results illustrate that better cell performance has been achieved with the cathodic humidity reduction. Cheng et al. [16] presented that decreasing $\mathrm{RHc}$ results in a much better performance of the PEM-FC.

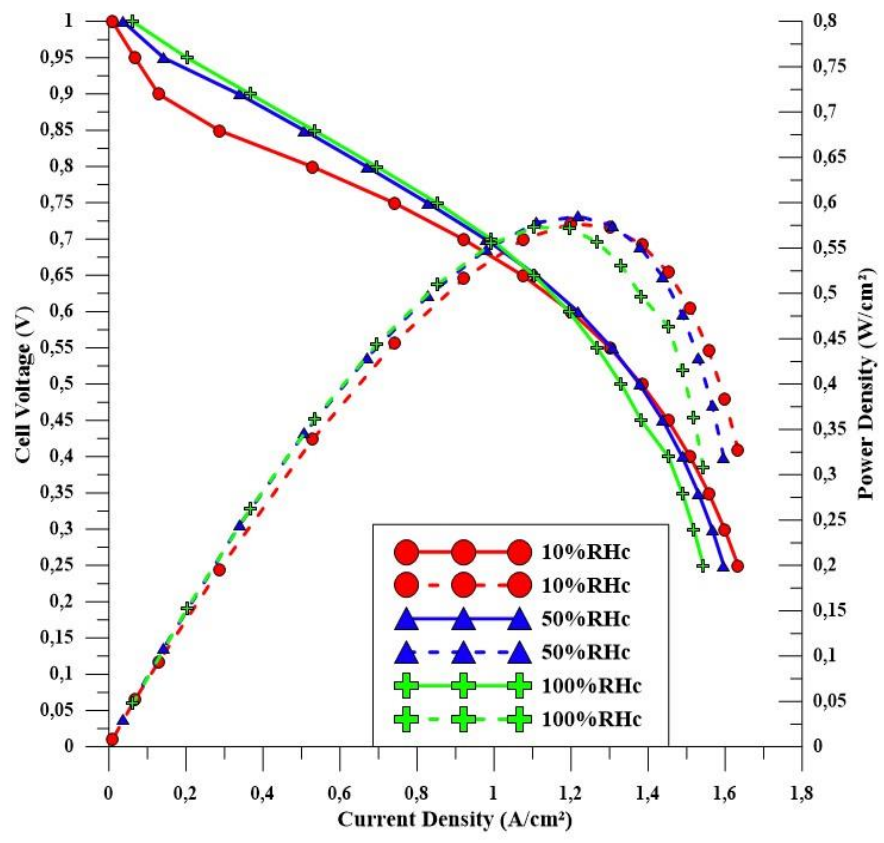

Fig. 5. Effect of RH at the cathode on the polarization curve at fully humidified anode condition for Z-type arrangement

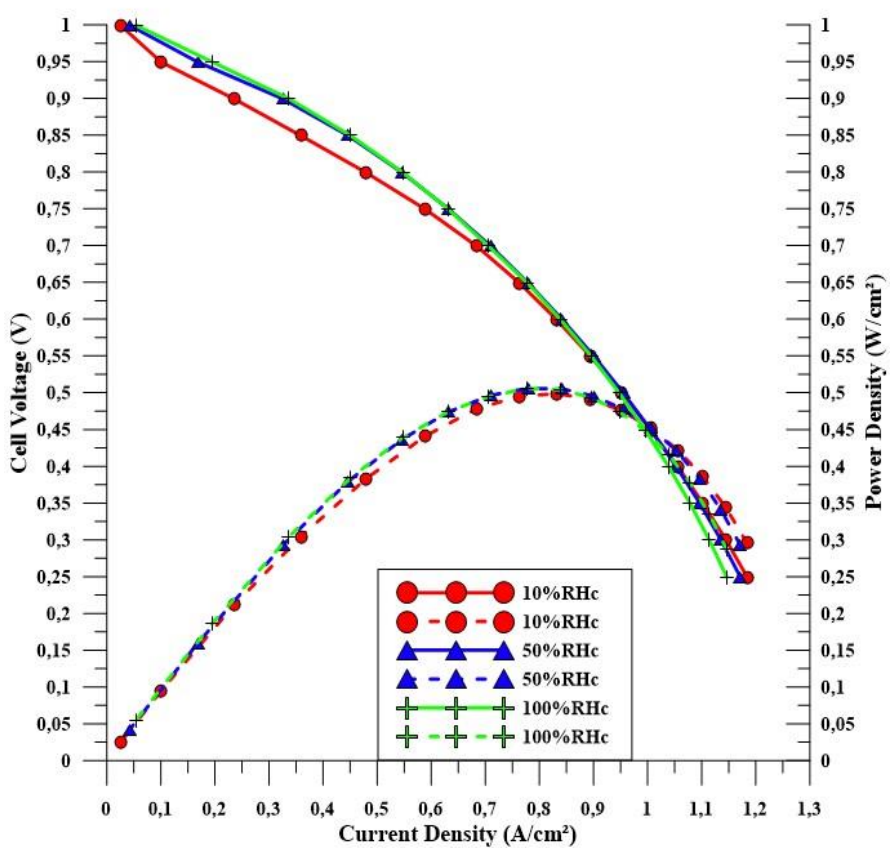

Fig. 6. Effect of RH at the cathode on the polarization curve at fully humidified anode condition for U-type arrangement

\subsection{Effect of the cell potential on temperature and water content}

The contours show that high temperatures were obtained at high current densities. The non-homogeneous temperature profile in the active area of the numerical model has appeared at low cell voltages. It has been observed that the temperature decreases from the flow channel inlet to the outlet due to the water accumulation. Fig. 
7 shows the water content of the Z-type arrangement at the interface of the GDL/CL layer on the cathode side when reactant relative humidity is $50 \%$. As the electrochemical reaction rate is high at low cell voltages, it was concluded that the water fraction formed in the cathode was the highest at 0.25 Volt. It was recorded that the highest temperature differences are $8 \mathrm{~K}, 4 \mathrm{~K}$, and $1 \mathrm{~K}$ at $0.25 \mathrm{~V}, 0.50 \mathrm{~V}$, and $0.75 \mathrm{~V}$ operating voltages, respectively, in Fig. 8 .

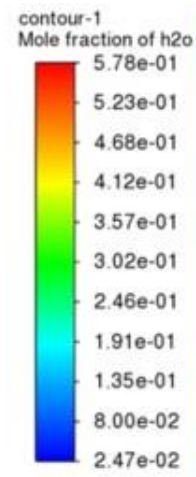

$$
\text { contour-1 }
$$

Mole fraction of $h 20$

$$
\begin{aligned}
& 5.03 e-01 \\
& 4.56 \mathrm{e}-01 \\
& 4.09 \mathrm{e}-01 \\
& 3.62 \mathrm{e}-01 \\
& 3.15 \mathrm{e}-01 \\
& 2.68 \mathrm{e}-01 \\
& 2.21 \mathrm{e}-01 \\
& 1.74 \mathrm{e}-01 \\
& 1.27 \mathrm{e}-01 \\
& 7.98 \mathrm{e}-02 \\
& 3.28 \mathrm{e}-02
\end{aligned}
$$

contour-1 Mole fraction of h2o

$4.46 e-01$
$4.05 e-01$
$3.65 e-01$
$3.24 e-01$
$2.83 e-01$
$2.43 e-01$
$2.02 e-01$
$1.61 e-01$
$1.20 e-01$
$7.98 e-02$
$3.91 e-02$

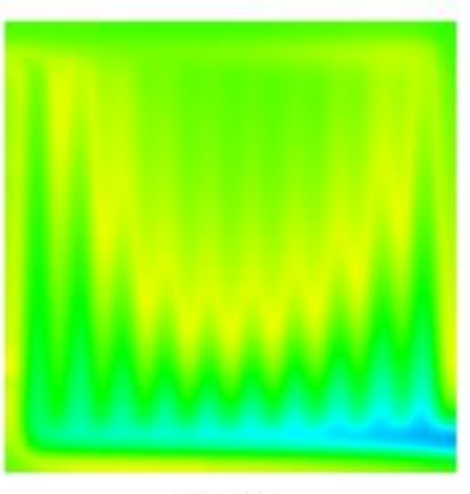

$0.25 \mathrm{~V}$

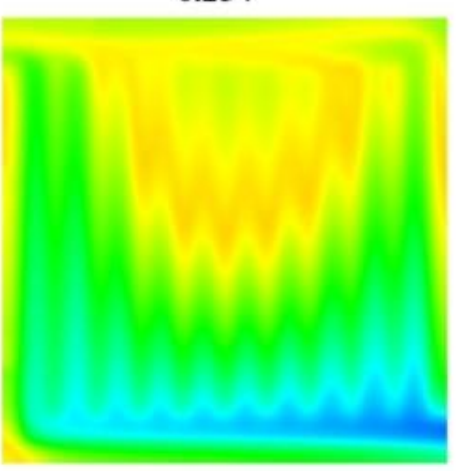

$0.50 \mathrm{~V}$

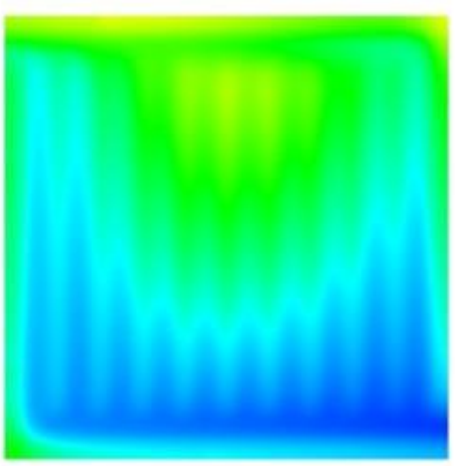

$0.75 \mathrm{~V}$

Fig. 7. Effect of the water mole fraction on the Z-type arrangement with co-flow pattern

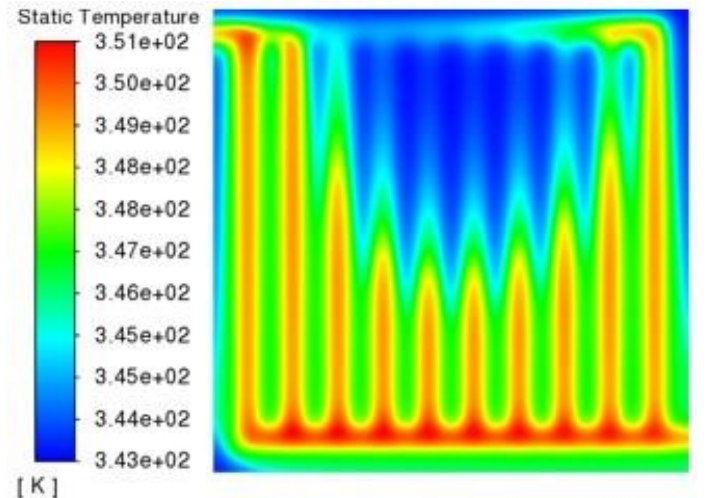

(a)

contour -1

Static Temperature

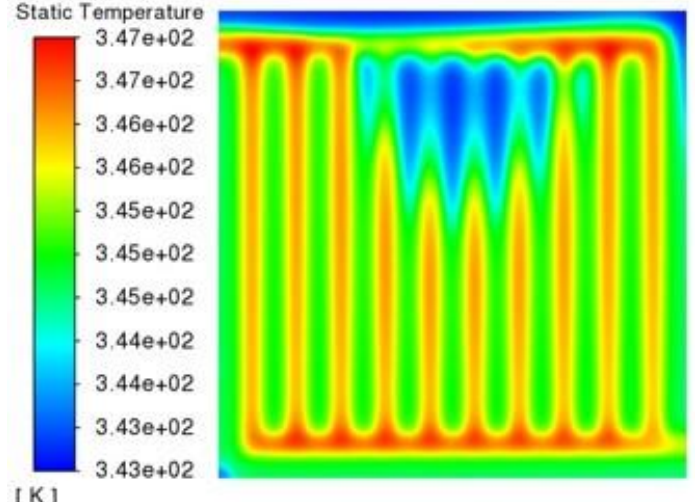

(b)

contour-1

Static Temperature

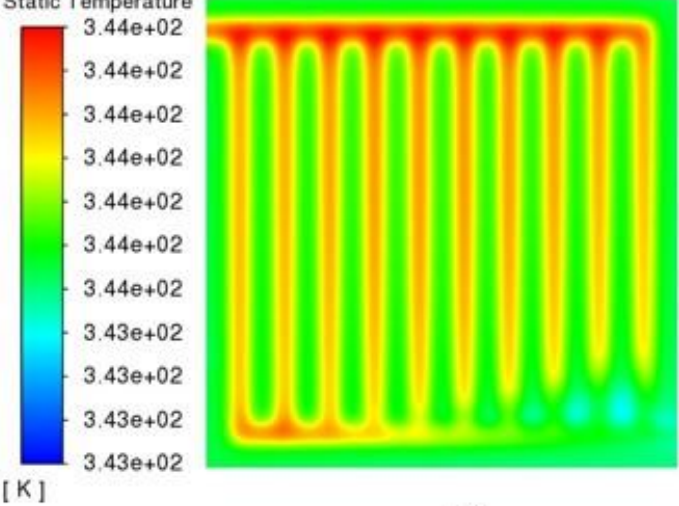

(c)

Fig. 8. Temperature distribution in the Z-type arrangement with coflow pattern, (a) $0.25 \mathrm{~V}$, (b) $0.50 \mathrm{~V}$, (c) $0.75 \mathrm{~V}$

\section{Conclusions}

This study presents a CFD analysis of the entire 3D PEMFC with a $4.41 \mathrm{~cm}^{2}$ active area for Z-type and U-type flow configurations concerning water management. The numerical work used air and hydrogen and investigated the overall performance with humidification at different levels. The results indicated that anode humidification generated better PEM-FC performance. The PEMFC performance could be improved by reducing $\mathrm{RHc}$ from $100 \%$ to $10 \%$ at lower cell voltages. It was recorded that the MEA power density increased from 0.5804 to 
$0.6041 \mathrm{~W} / \mathrm{cm}^{2}$ when the RHc was depressed from $100 \%$ to $10 \%$ at $0.40 \mathrm{~V}$ cell voltage for Z-type flow configuration. Water concentration decreases with descending RHc at the cathode, thus preventing cathode flooding, resulting in superior performance. Improving the relative humidity of the anode side will increase the power density on the polarization curve, known as the battery performance indicator. Anode humidification, which prevents membrane dehydration, improves hydrogen mass transfer across the membrane, and as a result, the electrochemical reaction accelerates. High RHa values have a positive impact on cell performance. For example, power density increased from 0.4680 to $0.4947 \mathrm{~W} / \mathrm{cm}^{2}$ when the RHa was enhanced from $10 \%$ to $100 \%$ at $0.70 \mathrm{~V}$ cell voltage for U-type flow configuration. A balance between blocking water flooding and significantly reducing proton transport resistance is essential in achieving the optimum performance condition in a PEM-FC. An appropriate level of humidification must be done to achieve this condition. Numerical results in this work are believed to beneficial in the PEMFC design. This study was limited to two different gas flow field designs, and the effect of relative humidity on cell performance was investigated numerically. A higher active area fuel cell model had to be developed for a noticeable difference in results, but the computational load will increase, so computers with high RAM capacity will be required.

On the other hand, compared to experimentally based approaches, CFD is an indispensable tool that reduces design and manufacture costs. Future work can investigate the effect of relative humidity on water management for various channel designs such as bio-inspired, interdigitated, pin-type, spiralserpentine, etc., or other operating parameters (temperature, pressure, and charge transfer coefficient) can be analyzed, and the study can be expanded. Maybe the fuel cell stack can be designed, and the battery performance examined. Numerous work on the effect of relative humidity on the single-channel single-cell conventional structure has been done. The most important feature that distinguishes the study from the others is to examine the influence of RH on two different flow field designs. Numerical results or findings will guide fuel cell stack manufacturers.

\section{Nomenclature}

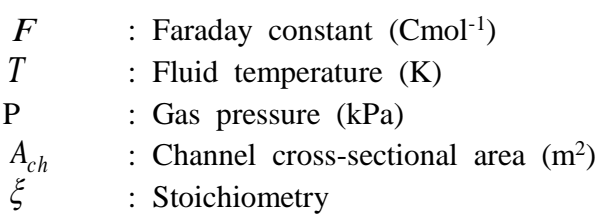

\section{Conflict of Interest Statement}

The authors declare that there is no conflict of interest in the study.

\section{Credit Author Statement}

Safiye Nur Özdemir: Conceptualization, Writing-original draft, Literature review

İmdat Taymaz: Conceptualization, Supervision

\section{References}

[1] Husar, A., Strahl, S. and Riera, J. Experimental characterization methodology for the identification of voltage losses of PEMFC: Applied to an open cathode stack. International Journal of Hydrogen Energy. 2012;37(8):7309-7315.

[2] Pei, P. et al. A review on water fault diagnosis of PEMFC associated with the pressure drop. Applied Energy. 2016;173:366-385.

[3] Zhang, G. and Jiao, K. Three-dimensional multi-phase simulation of PEMFC at high current density utilizing Eulerian-Eulerian model and two-fluid model. Energy Conversion and Management. 2018;176(June): 409-421.

[4] Shyu, J. C., Hsueh, K. L. and Tsau, F. Performance of proton exchange membrane fuel cells at elevated temperature. Energy Conversion and Management. 2011;52(12): 3415-3424.

[5] Ahmed, D. H. et al. Reactants flow behavior and water management for different current densities in PEMFC. International Journal of Heat and Mass Transfer. 2008;51(7-8): 2006-2019.

[6] Jian, Q. fei, Ma, G. qing and Qiu, X. liang. Influences of gas relative humidity on the temperature of membrane in PEMFC with interdigitated flow field. Renewable Energy. 2014;62:129-136.

[7] Yuan, W. et al. Model prediction of effects of operating parameters on proton exchange membrane fuel cell performance. Renewable Energy. 2010;35(3).

[8] Zhang, Jianlu et al. PEM fuel cell relative humidity (RH) and its effect on performance at high temperatures. Electrochimica Acta. 2008;53(16):5315-5321.

[9] Mohammadzadeh, K. et al. A numerical model for estimation of water droplet size in the anode channel of a proton exchange membrane fuel cell. Journal of Energy Storage. 2019; 26(October): 101021.

[10]Wang, Y. et al. Optimization of reactants relative humidity for high performance of polymer electrolyte membrane fuel cells with coflow and counter-flow configurations. Energy Conversion and Management. 2020;205(August 2019), p. 112369.

[11]Iranzo, A. et al. Investigation of the liquid water distributions in a $50 \mathrm{~cm} 2$ PEM fuel cell: Effects of reactants relative humidity, current density, and cathode stoichiometry. Energy. 2015; 82: 914-921.

[12]Ozen, D. N., Timurkutluk, B. and Altinisik, K. Effects of operation temperature and reactant gas humidity levels on performance of PEM fuel cells. Renewable and Sustainable Energy Reviews. 2016; 59: 1298-1306.

[13]Jeon, D. H. et al. The effect of relative humidity of the cathode on the performance and the uniformity of PEM fuel cells. International Journal of Hydrogen Energy. 2011;36(19):12499-12511.

[14]Wang, L. et al. A parametric study of PEM fuel cell performances. International Journal of Hydrogen Energy. 2003;28(11):1263-1272.

[15]Kahveci, E. E. and Taymaz, I. Effect of Humidification of the Reactant Gases in the Proton Exchange Membrane Fuel Cell. Journal of Clean Energy Technologies. 2015;3(5):356-359.

[16]Cheng, S. J., Miao, J. M. and Wu, S. J. Investigating the effects of operational factors on PEMFC performance based on CFD simulations using a three-level full-factorial design. Renewable Energy. 2012; 39(1): 250-260. 